\title{
Do Território à Multiterritorialidade entre Usuários, Trabalhadores e Pesquisadores em Saúde Mental
}

\author{
Marcos Adegas de Azambuja ${ }^{1}$ \\ ${ }^{1}$ Universidade Federal de Santa Maria, RS, Brasil.
}

\author{
João Leite Ferreira Neto $^{2}$ \\ ${ }^{2}$ Pontifícia Universidade Católica de Minas Gerais, \\ MG, Brasil.
}

\begin{abstract}
Resumo: Este artigo busca problematizar a noção de território na saúde mental por meio da experiência de trabalhadores, usuários e pesquisadores no município de Santa Maria-RS. Trabalhamos com pesquisa de documentos do campo da saúde e da saúde mental, buscando identificar o modo que a noção de território é apresentada nesses textos. Descrevemos e analisamos uma experiência desenvolvida por diversos atores sociais envolvidos na experiência ocorrida em Santa Maria, a partir de dois movimentos. O primeiro é o de usuários em direção à academia, e o segundo, o do cuidado em saúde do serviço de referência para além dos muros. A experiência de trânsito dos diferentes atores sociais em vivências de multiterritorialidades revelou-se um importante vetor de mudança subjetiva e institucional. Vimos em ambos a emergência de uma reivindicação por um direito mais extenso do que o simples acesso aos serviços públicos de saúde. Buscava-se também um "direito à cidade", ou mesmo um trânsito além dela. Enfim, uma busca pela ampliação da experiência de multiterritorialidade e as transformações decorrentes dela.
\end{abstract}

Palavras-chave: Saúde mental, Territorialidade, Inclusão social, Desinstitucionalização.

\section{From Territory to the Multi Territoriality among Users, Workers, and Researchers in Mental Health}

\begin{abstract}
This article seeks to problematize the notion of territory in mental health through the experience of workers, users, and researchers in the field of mental health in the municipality of Santa Maria/RS. We work with the research of documents of the field of health and mental health, trying to identify the way that the notion of territory is presented in these texts. We describe and analyze an experience developed by several social actors involved in the experience that occurred in Santa Maria / RS, from two movements. The first is that of users towards academia, and the second is that of the health care of the referral service beyond the walls. The experience of transit of the different social actors in multi-territorial experiences has proved to be an important vector of subjective and institutional change. We have seen in both movements the emergence of a claim for a more extensive right than simple access to public health services. A "right to the city," or even a transit beyond it. Finally, a search for the amplification of the multi territoriality experience and the transformations arising from it.
\end{abstract}

Keywords: Mental health, Territoriality, Social inclusion, Deinstitutionalization. 


\title{
Del Territorio a la Multiterritorialidad entre Usuarios, Trabajadores e Investigadores en Salud Mental
}

\begin{abstract}
Resumen: Este artículo busca problematizar la noción de territorio en la salud mental por medio de la experiencia de trabajadores, usuarios e investigadores en el municipio de Santa Maria/RS. Trabajamos con la investigación de documentos del campo de la salud y de la salud mental, buscando identificar el modo que la noción de territorio es presentada en esos textos. Describimos y analizamos una experiencia desarrollada por diversos actores sociales involucrados en la experiencia ocurrida en Santa Maria/RS, a partir de dos movimientos. El primero es de los usuarios hacia la academia, y el segundo es del cuidado en salud del servicio de referencia más allá de los muros. La experiencia de tránsito de los diferentes actores sociales en vivencias de multiterritorialidades se ha revelado un importante vector de cambio subjetivo e institucional. Vimos en ambos la emergencia de una reivindicación por un derecho más extenso que el simple acceso a los servicios públicos de salud. Se buscaba también un "derecho a la ciudad", o incluso un tránsito más allá de ella. En fin, una búsqueda por la ampliación de la experiencia de multiterritorialidad, y las transformaciones resultantes de ella.
\end{abstract}

Palabras clave: Salud mental, Territorialidad, Inclusión social, Desinstitucionalización.

\section{Introdução}

No processo de construção das políticas sociais dentro do marco da Constituição de 1988, o desenho traçado preconizava a descentralização, a municipalização e a territorialização das ações em um país portador de dimensões continentais. A saúde foi precursora da descentralização com o Sistema Único de Saúde (SUS).

Nas políticas públicas brasileiras, a noção de território tem ocupado um lugar cada vez mais central. Ele é pensado como um dos elementos potenciais para uma nova perspectiva redistributiva de gestão das ações das políticas sociais. Afinal, "a vida da população se dá em condições concretas, espacializadas, peculiares, nas quais o território e suas condições são determinantes" (Koga, 2003, p. 20).

Território, nas políticas de saúde, não designa o espaço físico inerte, mas deve ser entendido como sendo "um espaço em permanente construção, produtos de uma dinâmica social onde se tensionam sujeitos sociais postos na arena política", numa processualidade sempre inacabada e em mudança (Mendes, 1993, p. 166). Portanto, na visão do sanitarista, há uma conjunção necessária entre território, processos sociais, políticos e de subjetivação.

Para uma referência mais contemporânea a esse conceito, podemos nos referir ao estudo de Haesbaert (2009), que considera o território como "mediação espacial de poder, resulta da interação diferenciada entre as múltiplas dimensões desse poder, desde sua natureza mais estritamente política até seu caráter mais propriamente simbólico, passando pelas relações dentro do chamado poder econômico, indissociáveis da esfera jurídico-política" (p. 93).

Encontramos tanto na definição do sanitarista Mendes (1993) quanto na do geógrafo Haesbaert (2009) a descrição do território como portador de uma complexidade multidimensional. Este último aplica o conceito à vida cotidiana dizendo que todos atravessamos diariamente vários territórios como o da familiar, o do trabalho, entre outros, e nesses processos nos territorializamos e nos desterritorializamos. $\mathrm{O}$ que caracterizaria a experiência do novo milênio é a possibilidade da multiterritorialidade, que sempre existiu, mas atualmente está mais intensificada, "de experimentar diferentes territórios ao mesmo tempo, reconstruindo constantemente o nosso" (Haesbaert, 2009, p. 17). Cabe salientar a distinção entre multiterritórios e multiterritorialidade, já que no segundo percebe-se que deva existir certas operações para se habitar e existir nos espaços que não estão prontos e dados a priori. $\mathrm{O}$ autor acentua que essa possibilidade oferecida em nossos tempos não é socialmente distribuída de modo igualitário, mas grupos minoritários ainda lutam pelo território mínimo do abrigo, como é o caso dos usuários da saúde mental, entre 
outros. Com base nessa perspectiva, podemos dizer que o aumento do gradiente de multiterritorialidade se revela como um fator de produção de autonomia no campo da saúde mental.

Além disso, podemos problematizar o modelo asilar, centrado na internação hospitalar e o modelo da reforma psiquiátrica, centrado na busca permanente de reinserção social, a partir da noção, cara à saúde, de território. De um lado, temos um território fechado, no qual as relações de poder estão fixadas de modo dessimétrico e impedem a experiência da multiterritorialidade. Essa perspectiva de um território confinado, que cristaliza as relações de poder impedindo sua reversibilidade, aproxima-se do que Foucault chamou de "estados de dominação" (Foucault, 2004, p. 277). Do outro lado, temos a reinserção social e a possibilidade de uma atenção à saúde em serviços próximos ao território de moradia dos usuários. Mas isso não implica na reterriorizalização na vida do usuário restrita a esse território por ele habitado. A reinserção social deveria ampliar seu gradiente de multiterritorialidade experimentado pelos usuários, em seu "direito à cidade", seu livre trânsito entre diferentes territórios, a intensificação de suas "relações de poder como jogos estratégicos entre liberdades" (Foucault, 2004, p. 285). Isso envolve a não reprodução das assimetrias, vividas de modo inexorável no modelo asilar e nos cuidados à saúde oferecidos nos serviços comunitários abertos. Envolve escutar ativamente suas questões quanto ao tratamento oferecido, sua ligação com os medicamentos, e outras estratégias terapêuticas, estabelecendo relações menos prescritivas e mais negociadas, ampliando suas possibilidades de multiterritorialidades. A noção de território, tal como trabalhada por diversos autores no campo da saúde e em outros campos, e a noção de mutiterritorialidade proposta por Haesbaert (2009) serão eixos analíticos para discutirmos uma experiência ocorrida no cuidado em saúde mental, no município de Santa Maria, no estado do Rio Grande do Sul (RS).

O objetivo deste artigo é problematizar a noção de território na saúde mental por meio da experiência de trabalhadores, usuários e pesquisadores no campo da saúde mental no município de Santa Maria. Para isso, analisaremos como a noção de território é utilizada em documentos governamentais na saúde e na saúde mental; a seguir descreveremos analiticamente dois movimentos de desterritorialização e criação de vivências multiterritoriais na experiência de Santa Maria.

\section{Território em documentos governamentais de saúde}

Inicialmente, o território, em uma acepção mais ampliada semelhante às definições apontadas na Introdução, não foi diretamente abordado nos textos governamentais, a não ser pela referência jurídico-política mais convencional, associada à dimensão material do Estado, no enunciado "território nacional" (Bernardes; \& Nunes, 2018). Este uso está presente tanto na Constituição de 1988, quanto na Lei ${ }^{\circ}$ 8.080/1990, que regulamentou a criação do SUS. Contudo, uma diretriz importante reproduzida em ambos os documentos é a da "participação da comunidade" na organização das ações e serviços públicos de saúde (Brasil, 2018). Essa formulação, apesar de não mencionar a noção de território, indica aspectos que esse conceito pode trazer para o campo das políticas de saúde, ao falar da necessária proximidade espacial e institucional entre esses serviços e os usuários.

No parágrafo único do artigo $2^{\circ}$ da Política Nacional de Saúde Mental, um dos direitos dos usuários é serem tratados "em serviços comunitários de saúde mental" (Lei No 10.216, 2001). Essa designação indica o "comunitário" não apenas como uma proximidade do serviço com o local de residência do usuário, mas possui outra conotação referida aos modos de vida presentes naquele espaço, ou seja, alude ao conceito de território. A atual versão da Política Nacional de Saúde Mental fala em uma política de assistência comunitária em serviços de base territorial, trazendo o conceito para caracterizar de modo mais incisivo a antiga versão do "comunitário" (Brasil, 2018).

Outro elemento enfatizado na Política de 2001, no parágrafo primeiro de seu artigo $4^{\circ}$, é que: “[O] tratamento visará, como finalidade permanente, a reinserção social do paciente em seu meio" (Lei No $10.216,2001)$. Esta finalidade rompe com a Política anterior, que tinha na internação, em regime de longa permanência, em hospitais psiquiátricos, sua principal proposta terapêutica. Havia uma territorialização marcada pelo isolamento e confinamento dos usuários (Decreto No 24.559, 1934). Já a atual Política enfatiza que a internação durante a crise deve ser breve e humanizada, garantindo seu retorno para os serviços de base territorial (Brasil, 2018).

Os primeiros documentos normativos, como vimos, não utilizam a noção de território, mas possuem outros conceitos que têm interseção com o primeiro. Contudo, paulatinamente, a noção de ter- 
ritório, em uma acepção ampliada, passou a ocupar um lugar proeminente tanto nos documentos governamentais, quanto na literatura da área da saúde.

Ao abordarmos documentos mais recentes percebemos que as referências ao tema têm incidência crescente. Na Política Nacional de Atenção Básica - PNAB (Brasil, 2006), são 26 menções ao conceito de território sendo apenas cinco no sentido jurídico-político mais convencional. Porém, mais uma vez, a totalidade das referências aborda o território ou como lugar no qual vivem os usuários, ou descrevem a relação entre os serviços territorializados e sua população adscrita. Há também uma ênfase na importância de se conhecer a dinamicidade própria, existente no território e o trabalho com dados e indicadores de saúde. Busca-se, de um lado, o compromisso dos serviços em "monitorar e avaliar os indicadores do Pacto da Atenção Básica no seu território, divulgando anualmente os resultados alcançados" (Brasil, 2006, p. 13). De outro, busca-se envolver os trabalhadores em uma atuação pautada pelos indicadores, mas também comprometidos com a produção de dados do território: "atuar no território, realizando cadastramento domiciliar, diagnóstico situacional, ações dirigidas aos problemas de saúde de maneira pactuada com a comunidade onde atua" (p. 20).

Assim, de 1988 a 2006, a problematização da noção de território está restrita à proximidade dos serviços comunitários com os espaços de vida e moradia dos usuários. Há, sem dúvida, uma preocupação de oferta de serviços que conheça a singularidade própria dos diferentes territórios, como condição de possibilidade de qualificação do cuidado na Atenção Básica, não havendo uma problematização do gradiente de multiterritorialidade, objeto da preocupação de Haesbaert (2009), que já está presente na vida desses usuários. Grande parte das Unidades Básicas de Saúde (UBS) no país está localizada em territórios mais pauperizados dos municípios. Porém, boa parte de seus moradores já transita diariamente em outros territórios da cidade, principalmente em seus ambientes de trabalho, por vezes bem distantes de sua moradia. Mas essa dimensão não é abordada diretamente nos documentos buscados.

Essa visão restrita de território não é imune a riscos. Segundo Furtado, Oda, Broysow, \& Kapp (2016), "carrega até mesmo o risco de um processo no sentido oposto, pois ele fornece ao Estado uma legitimação adicional para exercer vigilância sobre toda a população de determinada área" (p. 9).
Localizamos apenas um único documento que discute a Saúde Mental na Atenção Básica (Brasil, 2013), problematizando em um curto parágrafo este conceito, de modo convergente com a discussão de multiterritorialidade. $\mathrm{O}$ documento possui 76 menções a território, que compõe inclusive o título de uma de suas seções: "A definição de cuidado, sofrimento, pessoa e território" (p. 27).

Os aspectos enfatizados na PNAB (2006) reaparecem nesse texto, tais como a base territorial dos serviços de saúde, o território associado ao local de moradia dos usuários, a importância do conhecimento do caráter singular do mesmo para planejamento das ações em saúde, defendendo a participação ativa dos usuários nesse processo.

Uma primeira novidade é o recurso ao conceito de território existencial, de Guattari, "Os territórios existenciais, que podem ser individuais ou de grupo, representam espaços e processos de circulação das subjetividades das pessoas. São territórios que se configuram/desconfiguram/reconfiguram a partir das possibilidades, agenciamentos e relações que as pessoas e grupos estabelecem entre si" (1992, p. 34). O conceito é explicado a partir da relação entre trabalhadores e usuários, na qual os primeiros devem se permitir deslocamentos de seus territórios existenciais subjetivos e fazer novos agenciamentos na direção ao cuidado integral da saúde dos usuários, não se contentando a uma conduta normativa ou prescritiva.

A segunda novidade que dialoga diretamente com a experiência de multiterritorialidades que aqui trazemos. Ao descrever a passagem entre o modelo asilar territorializado como um ambiente fechado e hierarquizado, alerta-se para o risco de não se restringir o território existencial dos usuários a seus locais de moradia.

O desafio que se coloca é, ao invés de criar circuitos paralelos e protegidos de vida para seus usuários, habitar os circuitos de trocas nos territórios da sociedade. Isso leva o desafio da saúde mental para além do SUS, já que para se realizar ele implica na abertura da sociedade para a sua própria diversidade (Brasil, 2013, p. 21).

Dois elementos destacam-se no parágrafo. $\mathrm{O}$ primeiro é o desafio do território de vida e dos serviços não ser tomado como um elemento de restrição das trocas nos outros territórios da sociedade, algo do tipo, permaneça nos seus serviços e com os seus. 
Mesmo reconhecendo a presença da multiterritorialidade entre o território de vida e dos serviços, trata-se de um gradiente baixo.

O segundo é que isso implica em mudanças que vão além da política pública, mas devem envolver a sociedade. Sabemos que essa tem sido uma estratégia desencadeada no campo da saúde mental desde o II Encontro Nacional dos Trabalhadores em Saúde Mental em Bauru, em 1987. À época, o diálogo com a Psiquiatria Democrática Italiana e sua ênfase na desinstitucionalização, para além da simples desospitalização, foi um elemento importante para uma mudança em direção à sociedade. Nesse Encontro foi produzida a consigna "por uma sociedade sem manicômios" e instituído o dia 18 de maio como o Dia Nacional da Luta Antimanicomial. Amaioria dos trabalhadores presentes eram profissionais não médicos, grande parte desses, psicólogos. Contou com a participação de intelectuais de diversas áreas, elaborou-se uma pauta de conceitos para instrumentalizar a luta pela reforma psiquiátrica, visando à autonomia do movimento em relação ao Estado. As diretrizes apontavam para um caminho de alargamento das fronteiras da luta para uma ação no interior da própria cultura, trazendo a discussão sobre a loucura para o cotidiano da sociedade, em uma estratégia que ampliava a atividade puramente assistencial e criava pontes entre as ações no âmbito do Estado com a sociedade civil (Bezerra Junior, 1994). Prevaleceu, desde então, um ideário de "desinstitucionalização ou da desconstrução/invenção" (Amarante, 1998, p. 93). Desde essa nova direção, seriam visadas alianças com a sociedade civil e os movimentos populares e com as associações de usuários e de familiares, a busca da rua, da imprensa, da opinião pública (Ferreira Neto, 2017).

\section{Movimento dos usuários para o território acadêmico}

Partiremos do relato de alguns efeitos de nossas experiências de pesquisa desenvolvida nos últimos quatro anos, em Santa Maria, no contexto de trabalhadores e usuários da saúde mental do SUS, a qual teve o objetivo de, principalmente, problematizar os psicofármacos como primeira e, muitas vezes, única proposta de tratamento para as pessoas com sofri- mento psíquico ${ }^{1}$. Falamos dos efeitos da experiência de pesquisa, pois a discussão que exporemos a seguir não é necessariamente oriunda dos materiais produzidos por ela, mas das relações e espaços de troca, que se estabeleceram com profissionais e usuários ao longo do processo. Isso corresponderia, sim, de uma atitude ética das relações construídas entre pesquisadores e participantes e, por conseguinte, de experiências que extrapolam o que poderia se delimitar, tradicionalmente, como próprio de um campo de pesquisa elaborado a priori em um projeto.

Um projeto de pesquisa, usualmente, demarca certa região de segurança para a manutenção das funções entre aqueles que pesquisam e os que são pesquisados. Em nosso caso, essa circunscrição se reforçava na principal intervenção do estudo, que ocorria em rodas de conversas em uma sala de aula, dentro do território acadêmico. Mesmo com a proposta de troca de experiências entre gestores, trabalhadores, usuários, acadêmicos, pretendendo uma perspectiva colaborativa, que intenta pesquisar com os outros e não sobre eles (Aubry, 2011; Leyva, \& Speed, 2008), sentíamos que o espaço físico já definia as figuras dos professores pesquisadores como regentes do que viria a se desenvolver. $\mathrm{O}$ desconforto fazia-se muito mais presente em nós pesquisadores, pois se acreditava que a maneira como interagíamos com os participantes já deveria ter superado há muito as tão discutidas dicotomias sujeito e objeto de pesquisa ${ }^{2}$. Todavia, por mais que, inclusive, tentássemos nos colocar como parceiros ou verbalizássemos diretamente sobre o caráter participativo da pesquisa, constantemente a passividade retornava a eles, dependendo de os pesquisadores colocá-los em ação.

Por um tempo, supúnhamos que sair da universidade seria a melhor forma de enfraquecer aquilo que Castro-Gómez (2007) denomina a colonialidade do saber - as heranças coloniais reproduzidas sistematicamente por um pensamento disciplinar e organização arbórea das estruturas acadêmicas, somados à preservação de um lugar privilegiado da produção do conhecimento. Posteriormente, percebemos que a entrada daquelas pessoas, especialmente, os usuários da saúde mental era precisamente o que estava nos

\footnotetext{
${ }^{1}$ A maioria de nossa experiência parte da pesquisa multicêntrica intitulada Implementação e descentralização da estratégia da gestão autônoma da medicação (GAM) no estado do RS: efeitos de disseminação (Universal MCTI/CNPQ nº 14/2014), coordenada pela professora Dra Analice Palombini da Universidade Federal do Rio Grande do Sul (UFRGS).

${ }^{2}$ Essas discussões na pesquisa em Ciências Humanas e Sociais despontam, no Brasil, desde o pioneiro Carlos Rodrigues Brandão (1984; 1987), no que se refere à pesquisa participante, até as mais atuais sobre a virada decolonial (Castro-Gómez, \& Grosfoguel, 2007).
} 
provocando a inflexão sobre nosso trabalho. Como aponta Bernardes (2018), há um jogo de estabilidade entre o território que se ocupa e o método que se usa e são as diferentes estratégias lançadas que incitam outras performances. Portanto, pesquisar com os outros, nos pareceu, dependia também da inclusão de pesquisar com o território, no sentido de transpassá-lo de um conceito para um vetor de produção de práticas (Bernardes; Nunes, 2018).

$\mathrm{Na}$ ocasião destes questionamentos acabava-se de viver, no Brasil, em 2016, o acontecimento das ocupações das escolas e universidades públicas - movimento constituído prioritariamente por estudantes que reagiam contra a Medida Provisória $\mathrm{n}^{\circ} 746$, a Proposta da Ementa Constitucional n 241 e o Projeto de Lei do Senado $n^{\circ} 193 / 2016$, o qual propõe o Programa Escola Sem Partido. Em nossa universidade não foi diferente, e o repúdio não se fez abandonando os espaços educativos, mas ocupando e procurando assumir diferentes modos de vivê-la. Trazer isso à memória, nos faz retornar à pesquisa frisando seu caráter intrínseco com a política, no sentido de considerar sua capacidade de produzir conhecimento localizado, datado e situado, assim como, de efetuar mundos e afetações outros (Haraway, 1995). Assim, passamos a olhar para os espaços privilegiados do universo acadêmico para professores e estudantes, em especial para os pesquisadores, e nos atentar para a rede complexa que se compõe em direção a um processo de estabilização de relações: a arquitetura dos prédios, os horários, os currículos e as disciplinas, os protocolos de presença e de avaliações, as reuniões, os computadores, os artigos científicos, os diferentes funcionários e suas titulações etc. São por essas contingências particulares em suas específicas associações com dispositivos, técnicas, pessoas e objetos que passamos a dar importância a aspectos de nós próprios e de nossa experiência: sermos pesquisadores, cientistas, professores, estudantes. Ao considerarmos um território como um coletivo de agências heterogêneas, isso nos ajudaria a pensar que nossas vidas, sentimentos, nossas epistemologias e nosso jeito de fazer pesquisa estariam atrelados à paisagem que nos compõe.

É nessa diversidade de elementos constituintes de certa política de pesquisa que os participantes adentraram e nos propiciaram observar pelo menos dois efeitos que resistiam entre si: uma aclimatação a esse ambiente versus uma desestabilização da experiência de uma "pesquisa pronta", o que permitiu indagar as circunstâncias de produção dos fatos científicos. Neste tema, Latour (1999), propõe a metáfora da caixa-preta para os fatos, artefatos, enfim, objetos de conhecimento científicos ou técnicos que estão totalmente consagrados. Destampar a caixa-preta das práticas de pesquisa estabelecidas permitiria conhecer as redes heterogêneas que se concentraram no apaziguar das controvérsias e interrogações em torno delas $^{3}$. Mexer nessa caixa não se deveu a um trabalho analítico, mas com a direta interferência no cotidiano do pesquisar, no encontro com aqueles que faziam parte do processo.

Abriu-se, assim, uma série de circuitos exclusivos a nós que passaram a ser habitados ou visitados pelos participantes da pesquisa. Aos poucos, profissionais e usuários foram convidados a se inserir nas reuniões semanais do grupo de pesquisa, nas quais se tratava de todos os assuntos concernentes a ela, como preparação das reuniões subsequentes, transcrição dos encontros gravados, análise e discussão dos materiais etc. Curiosamente, foram os usuários, mais precisamente três, que se interessaram por ocupar esse local - talvez, por disponibilidade de tempo, decerto pelo possível acesso a um espaço educativo universitário. Pode-se colocar como fator significativo, que foi a partir do cruzamento de "mundos" diferentes - dos acadêmicos e dos usuários da saúde mental - que se iniciou o questionamento sobre o que seria de fato pesquisar com os outros e que acarretou a ampliação do gradiente de multiterritorialidade, tanto dos usuários, quanto dos acadêmicos, permitindo não somente a experimentação das diferenças, quanto a transformação dos sujeitos e dos territórios (Haesbaert, 2009).

A partilha semanal no meio acadêmico com os usuários que, usualmente, como eles mesmos nos diziam, se mantinham no trajeto da casa para o Centros de Atenção Psicossocial (CAPS) e dali para casa, os levavam a fascínios e disposições sortidas, como publicar um livro, viajar para o exterior, voltar a estu-

\footnotetext{
${ }^{3}$ Talvez, as questões que estamos abordando neste movimento se aproximem mais da imagem da caixa-cinza, sugerida por Pedro (2010), ou de objetos instáveis e mais quentes, conforme Latour (1999). Isso se refere a uma técnica que ainda não está completamente estabelecida, como é o caso das pesquisas em Ciências Humanas e Sociais.
} 
dar, aprender outra língua, organizar eventos, parar de usar medicação psiquiátrica, moderar grupos a fim de ajudar outros que passavam por situações similares a eles. De nossa parte, que, com muito mais acesso e desimpedimentos sócio econômicos que eles, nos acondicionávamos ao perímetro da casa para universidade e dali para casa, os encontros nos arrancavam do lugar de produtores do conhecimento e nos faziam desejosos de compartilhar outros espaços com eles. Como Marques, Palombini, Passos e Campos (2013) já prenunciam no próprio título de seu texto, as vozes dos usuários de saúde mental nos levam a transformação de nós mesmos, principalmente, a mudar de lugar e produzir diferença.

Não somente suas vozes, mas suas presenças físicas passaram a abranger outros âmbitos: eles foram convidados a participar de aulas em disciplinas de cursos de graduação em Psicologia e Terapia Ocupacional, de especialização em saúde mental e de residência multiprofissional em saúde mental. Foram palestrantes em duas atividades organizadas por Coordenadorias Regionais de Saúde do Estado do Rio Grande do Sul e nos auxiliaram como apoiadores em um projeto de extensão, no qual se visitava os serviços que ofereciam grupos da Gestão Autônoma da Medicação $(\mathrm{GAM})^{4}$ na região Centro-Oeste do Rio Grande do Sul. Em todos esses momentos, diferente da costumeira desatenção ao conteúdo e ao ministrante nesses ambientes educativos, a plateia mantinha-se compenetrada àqueles inusitados. Muitos se emocionavam, outros agradeciam a oportunidade de finalmente ter uma aula prática, conhecer outra realidade, inteirar-se sobre aqueles que vivem com as marcas do diagnóstico e do medicamento psiquiátrico.

Como mencionado por Senna e Azambuja (2019), ouvir de um palestrante usuário da saúde mental, em uma sala de aula, de que "todo mundo fede igual aqui” (p. 4) e, em seguida, receber a provocação "Não sei, eu queria entender, por que será que vocês estão quietos? Será que é por que vocês estão com vergonha, ou por que não conseguem se colocar no lugar da gente, da doença, de quem sofre?” (p. 4), é o que retirava estudantes de seus territórios de silêncios e de imobilidades para colocarem-se em diálogo com eles.

Quietude e inércia acadêmica que pode estar, para além das forças disciplinares, a serviço de uma escuta que captura o outro para posteriormente falar por ele. Com essa primeira cena, talvez, estejamos sendo empurrados a considerar aquilo que Spivak (2010), diz sobre a relação dos intelectuais e o outro da pesquisa: o perigo de constituí-lo como subalterno e colonizado, no momento em que sua fala é intermediada pela voz acadêmica, que se coloca em posição de reivindicar algo em nome de um outro. A autora revela o lugar incômodo e a cumplicidade do intelectual que julga poder falar pelo outro e, por meio dele, construir um discurso de resistência. Agir dessa forma, argumenta ela, é reproduzir as estruturas de poder e opressão, mantendo o subalterno silenciado, sem lhe oferecer uma posição, um espaço de onde possa falar, se articular e, principalmente, ser ouvido. Enfim, haveríamos de fazer o exercício de recusa da fala pelo subalterno, para a criação de vozes contra a subalternidade.

Com esse movimento vemos uma reversão do tão usual trajeto, visualizado nos documentos governamentais, em direção ao território de assistência, de atenção aos cidadãos. A universidade em seu projeto extensionista também segue a mesma premissa. Atuar no território dos usuários, da comunidade pode, de certa maneira, manter distantes e intactos os lugares de onde saímos. Essa estratégia de organização entre os territórios dos cidadãos e os especialistas se enlaça muito com aquilo que Lyotard (2004) analisa como as duas metanarrativas, que servem para legitimar a produção e a estruturação dos conhecimentos na modernidade: a ideia da educação do povo, ou seja, do direito das pessoas desfrutarem dos avanços da ciência e tecnologia em direção ao progresso; e a narrativa do aperfeiçoamento moral da humanidade, isto é, os especialistas - sem dúvida, falamos daqueles egressos das universidades -, além do serviço técnico de suas profissões, também são sujeitos capazes de "educar" moralmente o resto da sociedade. Portanto, o convite aos usuários da saúde mental para habitar o território acadêmico serviu para tensionar essas contingências históricas da formação e funcionamento de uma série de práticas educativas e de pesquisa com as quais estabelecemos relações particulares, estáveis, sentidas como naturais e necessárias, determinando as capacidades de cada elemento em relação, intensificando a experiência de multiterritorialidade de todos os envolvidos.

${ }^{4}$ Para acessar o guia GAM do usuário e do moderador cf. https://www.fcm.unicamp.br/fcm/laboratorio-saude-coletiva-e-saude-mental-interfaces. 


\section{Movimento dos CAPS para as ruas}

Passemos aos espaços concernentes às práticas em saúde mental na rede pública de Santa Maria. Aqui encontra-se o que muitos já conhecem: CAPS, Estratégias de Saúde da Família (ESF), Unidades Básicas de Saúde (UBS), Unidades de Pronto Atendimento (UPA), Hospitais, Unidades de internação, mas também a comunidade, as associações, as casas, o açougue, o lixeiro, as pessoas, o lixo, o churrasco, as ruas, a gurizada do hip-hop, as paradas de ônibus, o futebol, os tiros, a feira da dona Lourdes, as carroças, a padaria, a polícia, o candomblé, o espetinho de esquina, a cachaça, os cachorros e gatos, a porrada etc. Quais as forças que podem nos atravessar ou que deixamos passar, já que, pelas atribulações profissionais ou acadêmicas, podemos estar tão distantes destes territórios (não porque não gostaríamos, mas porque aquilo que nos capacita enquanto pesquisadores, cientistas, professores, estudantes, ou profissionais da saúde mental, talvez, tomem o nosso tempo)? E se essas distâncias, por vezes, podem se tornar intransponíveis, como intensificar a multiterritorialidade?

Como se sabe, os CAPS fazem parte do processo de desinstitucionalização psiquiátrica e, dentro dos serviços que substituem as práticas de internação, são responsáveis por tecer a rede de cuidado em saúde mental, passando a funcionar como ordenadores desta rede (Portaria $n^{\circ} 336,2002$ ). No entanto, alguns estudos apontam para a necessidade de avançarmos no processo de atenção em saúde mental para além de um cuidado de portas abertas, isto é, um serviço capaz de articular-se ao território vivo da cidade, para superar a lógica manicomial e a consequente cronificação dos usuários, que permanece independentemente do fim dos hospitais psiquiátricos (Alverga, \& Dimenstein, 2006; Barros, Mângia, 2007; Ferreira, Sampaio, Souza, Oliveira, \& Gomes, 2017). Em nossa experiência de pesquisa, não são diferentes as dificuldades encontradas a fim de criar rupturas para que a "loucura circule" - seus sentidos práticos e discursivos - para além do espaço dos serviços de saúde mental.

Em participações de reuniões de equipe em um CAPS da cidade, as(os) profissionais não suportavam mais ter que permanecer tanto tempo dentro do serviço com tanta "loucura". Uma delas relatou com certo pesar de, geralmente, pegar o ônibus, ao fim do expediente, com alguns usuários e, às vezes, eles a procurarem em sua casa. Era de comum acordo que percebiam o serviço e os profissionais como, talvez, a única rede de relações mais estável desses usuários - o que os faziam compreender a problemática social que envolvia essas pessoas, contudo insuficiente para lidar com a intensidade da convivência. Ao passo que um dos pesquisadores indagou se a questão a se colocar não seria de abandonar o emprego ou, se não aguentavam mais ficar ali dentro, por que não trabalhar fora dali, na rua? Onde estaria o projeto da política de saúde mental de trabalho territorial para reinserção social?

Usualmente, quando falávamos em ação no território, este era associado à Atenção Básica, os dois termos cobriam um espaço similar. Talvez, estivéssemos imersos em uma noção funcional de território, pois quando se aventava sobre reinserção das pessoas com sofrimento psíquico grave, se remetia ao local onde elas moravam. Fazia sentido para equipe implementar ações na Atenção Básica, mas o movimento se dispunha impedido, mesmo com tamanho desconforto dentro do CAPS, pois havia o entendimento de que no território outros serviços deveriam atuar. Teríamos aqui uma acepção de território como espaço “[...] adjacente ao serviço de saúde, cujos moradores e ou frequentadores podem fazer uso deste serviço" (Furtado et al., 2016, p. 7).

De certa forma, trabalhar no território estava definido pelas divisões preconizadas no SUS e seguindo um sentido mais corriqueiro, como uma área. Além disso, em nossa situação, o CAPS sequer era compreendido como mais um componente territorial, já que o território seria uma região onde vive o usuário e o CAPS se encontra em uma área mais central da cidade, afastada das casas da maioria daqueles que frequentam o serviço, precisava-se, como muito se falava, ir ao território. Assim, o CAPS e boa parte da cidade eram algo que se tornava uma exterioridade com relação a essa noção.

Nesta época, apresentavam-se pelo menos três funcionamentos no serviço identificados nas reuniões. Primeiro, sem alterar as atividades do CAPS, se empenhar para que os usuários ficassem mais tempo fora daquele serviço, os encaminhando às ESF de seus territórios. Segundo, junto ao anterior, selecionar os encaminhamentos dos diversos equipamentos do município, aceitando somente aqueles que teriam "perfil" para CAPS, no caso, pessoas com sofrimento psíquico severo e persistente. Terceiro, de forma mais discreta e esporádica, havia um grupo menor que já oferecia atividades nas proximidades onde estes usu- 
ários moravam ou em áreas da cidade de pouca circulação para eles.

Interessante notar que, ao longo dos anos da pesquisa, foi a indagação sobre o movimento de ir ao lugar em que moravam os usuários que fez com que a concepção de território se modificasse. Por um lado, deslocar-se para o território era para profissionais e pesquisadores conhecerem, às vezes, pela primeira vez, de perto, os motivos pelos quais se falava em Reforma Psiquiátrica, em cidadania, luta por direitos etc., pois se experienciava a miséria e o desinvestimento do Estado nessas regiões. Por outro, foi possível ampliar a compreensão dos motivos pelos quais os usuários se utilizam tanto do CAPS. Há, parece-nos, haver mais ofertas de atividades neste local, em relação às da comunidade. Ali se alimentam, conversam, tomam chimarrão, formam amizades, amores e, além disso, estão em contato com outras pessoas de outros cantos da cidade.

Portanto, apresenta-se um paradoxo, no qual muitos usuários querem sair do território onde sempre se entendeu que a política de saúde mental deve intervir, enquanto os profissionais querem mover os usuários para fora do CAPS, local que tem para estes muito mais sentidos do que somente buscar um tratamento. A tensão que se produz no encontro, de um lado, daqueles que lutam por mais direitos em seu viver e, de outro lado, daqueles que tem por ofício oferecer cuidado em saúde mental é o que começa a desenhar a experiência da multiterritorialidade nas práticas cotidianas.

Este parece-nos o ponto nodal que disparou um movimento lento em direção à cidade, não somente no sentido de circular por ela, mas, outrossim, de considerar as questões de poder e disputa presentes nos diversos territórios que podem ter implicações relevantes para as pessoas que acessam o serviço. Para além da concepção geográfica citada anteriormente, o território passa a ser entendido como um campo estratégico de avaliação, regulação e movimentação da população. Conforme analisam Hillesheim e Bernardes (2015), as políticas de inclusão em nossa sociedade orientadas pela coerência neoliberal, funcionam pela gestão da vida tendo como pressuposto a liberdade. Se não é mais fundamental a exclusão pela direção do internamento, criam-se dispositivos "[...] tanto de mapeamento e esquadrinhamento das condutas, quanto na prevenção ao risco, isto é, ações dirigidas a indivíduos e grupos potencialmente peri- gosos" (p. 136). A exclusão em liberdade acontece no esquema de normalização dos sujeitos pela integração ao mercado e ao Estado, participando e sendo identificados nos diferentes níveis do diagrama populacional. É ao acessar as políticas ofertadas (educacional, de assistência social, de saúde, entre outras) que são encontradas as irregularidades nas pessoas com relação à norma e, por conseguinte, emerge o sujeito patológico, desorganizado, disfuncional etc.

Trabalhadores e usuários podem interferir nestes procedimentos principalmente ao considerar o espaço urbano na qualidade de recurso terapêutico e de outras formas de viver, enfim, conforme Haesbert (2013), de invenção política. Quer dizer, território "desdobra-se ao longo de um continuum que vai da dominação político-econômica mais 'concreta' e 'funcional' à apropriação mais subjetiva e/ou 'cultural-simbólica'” (Haesbart, 2009, p. 95-96). Aperceber-se do campo de afetações presente na insuportável permanência no CAPS, por parte de uns, ou na comunidade, por parte de outros, é a oportunidade de dar destaques às lutas e conflitos infligidos na sustentação de determinadas formas de produzir conhecimento e relação sobre os processos de subjetivação e de objetivação da loucura. Com isso, as repercussões ocorrem tanto dentro quanto fora do serviço.

Artesanato e cozinha são pensados agora como meios para geração de renda. Esse conceito transborda tais atividades ao ponto de surgirem usuários buscando sustento financeiro, independente das intervenções no serviço. Grupos de horta de diferentes CAPS decidem se encontrar, proporcionando interface entre profissionais e usuários de diferentes serviços. Cria-se uma associação dos usuários, que fortalece as assembleias semanais no CAPS, os faz procurar uma sede e, inclusive, um deles começa a ocupar uma cadeira no Conselho Municipal de Saúde. Circular pela cidade fez com que alguns usuários descobrissem oficinas de teatro ofertadas pelo município. Um deles comunicou aos profissionais que incluíssem em seu Plano Terapêutico Singular essa atividade, atitude que rompeu com a lógica de que seria o serviço quem ofertaria as possibilidades terapêuticas aos usuários.

Dentro do serviço ampliou-se a inserção de acadêmicos, sejam estagiários ou residentes, do mesmo modo, outras abordagens foram iniciadas, como grupos de Gestão Autônoma da Medicação e de Ouvidores de Vozes - espaços de escuta e problematização de dois eixos que sustentam historicamente as prá- 
ticas 'psi' sobre a loucura: o uso dos psicofármacos e o apagamento do delírio. Uma usuária disse preferir muito mais esses grupos que a dispõe olhar para fora, para as coisas da vida, do que os grupos psicoterapêuticos, que a provocam olhar para dentro, para os problemas interiores. Ela explica que nestes, além de contar sobre suas histórias traumáticas, tem de ouvir os sofrimentos de todos do grupo e, ao final do encontro, muitos acabavam solicitando atendimento individual para dar conta de tamanha exposição de carga emocional. Já naqueles se fala de problemas também, mas se pensa em como lidar com essas coisas na vida, os preconceitos sobre a loucura, os direitos e exercício de cidadania.

Vemos, portanto, que, ao buscar se ampliar os lugares de trânsito dos usuários na cidade, esses passaram a reivindicar a frequência em novos locais, que não estavam oficialmente previstos nas políticas. É uma demanda por um direito mais extenso do que o acesso aos serviços públicos de saúde, que pode ser considerado como uma busca por um "direito à cidade", à vida urbana, "aos locais de encontro e de trocas, aos ritmos de vida e empregos do tempo que permitem o uso pleno e inteiro desses momentos, locais etc. (Lefebvre, 2001, p.143).

\section{Considerações finais}

Este estudo buscou problematizar a noção de território na saúde mental por meio da experiência de trabalhadores, usuários e pesquisadores no município de Santa Maria. Trabalhamos com a noção de território proposta por Haesbaert (2009) e com sua ênfase sobre a intensificação da multiterritorialidade na atualidade, que caminha juntamente com uma restrição desta junto a grupos minoritários. A análise de como alguns textos governamentais aborda o tema do território convergiu para a diretriz de oferta de serviços comunitários onde moram os usuários. Sem desconhecer a importância disso, no que diz respeito ao acesso aos serviços por parte da população mais pobre, há que se considerar sua dimensão restritiva da vivência mais extensa de multiterritorialidades - 0 encontro desterritorializante entre os diferentes territórios.

Na experiência descrita e analisada de trabalhadores, usuários e pesquisadores no campo da saúde mental no município de Santa Maria, observamos movimentos de desterritorialização que permitiram o aumento do gradiente de multiterritorialidade dos diversos atores envolvidos. No primeiro, dos usuários no espaço acadêmico, foi rompido o circuito casa-CAPS-casa, e o trânsito pela Universidade não se restringiu ao contexto da pesquisa, mas penetrou na graduação, na cooperação em outros projetos, nas viagens e trabalhos em outras cidades e no impacto transformador que eles produziram entre os acadêmicos e sobre si mesmos.

No segundo movimento, dos CAPS para às ruas, $\mathrm{e}$ não apenas as de suas residências, mas as da cidade, ocorreu o encontro com outros locais, outras atividades, que passaram a ser incluídas em seus Planos Terapêuticos Singulares, a partir daí construídos em colaboração mais extensa e intensa. Emergiu nesse momento a reivindicação de um direito que ultrapassava a universalidade do acesso aos serviços, mas visava um direito à cidade multiterritorial.

Nesse sentido, cabe ressaltar a imbricação entre os territórios e a produção de práticas na pesquisa e na atuação profissional em saúde mental. Para pesquisadores e trabalhadores incluir, enquanto espectro de problematização as formas com as quais habitamos os espaços, pode nos levar a rearranjos do modo como intervimos em nossas atividades, das mais complexas as mais cotidianas. Essas transformações ligam-se às considerações sobre as interfaces de lutas entre o político e o cultural, desde as fronteiras de uma nação a outra até os limites de nossa corporeidade. Intervir com os outros e com os territórios nos permite visualizar e criar desvios aos etnocentrismos e colonialismos nos discursos e práticas em saúde mental. Essas rupturas são incrementadas, ou melhor, radicalizadas pela perspectiva decolonial no sentido daquilo que se aventa com as propostas participativas, colaborativas. Abrir-se a outros espaços, assim como permitir a entrada de outros - humanos e não humanos - em nossos territórios supostamente constituídos e estáveis, torna-se oportunidade para afirmar as relações de codependência entre a materialidade do lugar e seu uso, os processos históricos, os modos como conduzimos nossas vidas e de outros. Enfim, este texto teve como uma de suas principais características trazer a discussão sobre território, mostrar como ele aparece para além da política de saúde e suas diretrizes e, portanto, trabalhar e pensar com os territórios pode ser a entrada de mais um componente no jogo de forças das condições de existência que performam as diferentes maneiras de fazer saúde mental. 


\section{Referências}

Alverga, A. R. Dimenstein, M. (2006). A reforma psiquiátrica e os desafios na desinstitucionalização da loucura. Interface - Comunicação, Saúde, Educação, 10(20), 299-316. https://dx.doi.org/10.1590/S1414-32832006000200003

Amarante, P. (org). (1998) Loucos pela vida: A trajetória da reforma psiquiátrica no Brasil (2a ed.). Rio de Janeiro, RJ: Fiocruz.

Aubry, A. (2011). Otro modo de hacer ciencia. Miseria y rebeldía de las ciencias sociales. In: B. Baronnet, M. Mora Bayo, \& R. Stahler-Sholk (orgs.), Luchas "muy otras": Zapatismo y autonomía en las comunidades indigenas de Chiapas (pp. 59-70). México, DF: UAM-X: CIESAS: UACH.

Barros J. O., \& Mângia, E. F. (2007). Rede social e atenção às pessoas com transtornos mentais: novo desafio para os serviços de saúde mental. Revista de Terapia Ocupacional da Universidade de São Paulo, 18(3):135-42. https:// doi.org/10.11606/issn.2238-6149.v18i3p135-142

Bernardes, A. G. (2018). Pesquisar com o território: algumas apostas metodológicas. Psicologia: Ciência e Profissão, 38(2), 291-300. https://doi.org/10.1590/1982-3703003492017

Bernardes, A. G., \& Nunes, J. A. (2018). Território e sistemas vitais na saúde. Revista Polis e Psique, 8(2), 46-66. https://doi.org/10.22456/2238-152X.74029

Bezerra Junior, B. (1994). "De médico e louco cada um tem um pouco: o campo psiquiátrico no Brasil nos anos oitenta. In R. Guimarães, \& A. W. Tavares (orgs.), Saúde e sociedade no Brasil: anos 80 (pp. 171-191). Rio de Janeiro: Relume Dumará.

Brandão, C. R. (1984). Pesquisa participante. São Paulo, SP: Brasiliense.

Brandão, C. R. (1987). Repensando a pesquisa participante. São Paulo, SP: Brasiliense.

Brasil (2006). Ministério da Saúde. Secretaria de Atenção Básica. Política nacional de atenção básica (Série Pactos pela Saúde 2006, v. 4). Brasília, DF: o autor.

Brasil. (2013). Ministério da Saúde. Secretaria de Atenção à Saúde. Saúde mental (Cadernos de Atenção Básica, 34). Brasília, DF: o autor.

Brasil. (2018). Ministério da Saúde. Política nacional de saúde mental, álcool e outras drogas Brasília, DF: o autor.

Castro-Gómez, S. (2007). Decolonizar la universidad. La hybris del punto cero y el diálogo de saberes. In S. Castro-Gómez, \& R. Grosfoguel (orgs.), El giro decolonial: reflexiones para una diversidad epistémica más allá del capitalismo global (pp. 79-92). Bogotá: Siglo del Hombre.

Castro-Gómez, S. Grosfoguel, R. (2007). Prólogo; Giro decolonial, teoría crítica y pensamiento heterárquico. In S. Castro-Gómez, \& R. Grosfoguel (orgs.), El giro decolonial: reflexiones para una diversidad epistémica más allá del capitalismo global (pp. 9-24). Bogotá: Siglo del Hombre.

Decreto No 24.559, de 3 de julho de 1934. Dispõe sôbre a profilaxia mental, a assistência e proteção á pessôa e aos bens dos psicopatas, a fiscalização dos serviços psiquiátricos e dá outras providências. Diário Oficial da União, 14 de julho de 1934.

Ferreira, T. P. S., Sampaio, J., Souza, A. C. N., Oliveira, D. L., \& Gomes, L. B. (2017). Produção do cuidado em Saúde Mental: desafios para além dos muros institucionais. Interface - Comunicação, Saúde, Educação, 21(61), 373-384. https://dx.doi.org/10.1590/1807-57622016.0139

Ferreira Neto, J. L. (2017) Psicologia, políticas públicas e o SUS (2a ed. ampliada). São Paulo, SP: Escuta.

Foucault, M. (2004). A ética do cuidado de si como prática da liberdade. In M. B. Motta (Org.), Ética, sexualidade, política (pp. 264-287; Ditos e escritos, V.; E. Monteiro, \& I. Barbosa, Trad.) Rio de Janeiro, rj: Forense Universitária. (Original publicado em 1984).

Furtado, J., Oda, W. Y., Borysow, I. C., \& Kapp, S. (2016). A concepção de território na Saúde Mental. Cadernos de Saúde Pública, 39(9), p. 1-15. httpS://doi.org/10.1590/0102-311x00059116

Guattari, F. (1992) Caosmose: Um novo paradigma estético. Rio de Janeiro: Ed. 34.

Haesbaert, R. (2009) Do fim dos territórios à multiterritorialidade (4a. ed. revista). Rio de Janeiro, RJ: Bertrand do Brasil. 
Haesbaert, R. (2013). Territórios alternativos. São Paulo, SP: Contexto.

Haraway, D. (1995). Saberes localizados: A questão da ciência para o feminismo e o privilégio da perspectiva parcial. Cadernos Pagu, (5), 7-41.

Hillesheim, B., \& Bernardes, A. G. (2015). Políticas de Inclusão: A arte de governar a partir da liberdade. Psicologia em Estudo, Maringá, 20(1), 129-137. https://doi.org/10.4025/psicolestud.v20i1.25675

Koga, D. (2003) Medidas de cidades: Entre territórios de vida e territórios vividos. São Paulo, SP: Cortez.

Latour, B. (1999). Ciência em ação: Como seguir cientistas e engenheiros sociedade afora. São Paulo, SP: UNESP.

Lefebvre, H. (2001). O direito à cidade. São Paulo, SP: Centauro.

Lei No 10.216, de 6 de abril de 2001. Dispõe sobre a proteção e os direitos das pessoas portadoras de transtornos mentais e redireciona o modelo assistencial em saúde mental. Diário Oficial da União, 9 de abril de 2001.

Leyva, X., \& Speed, S. (2008). Hacia la investigación descolonizada: Nuestra experiencia de co-labor. In X. Leyva, A. Burguete, \& S. Speed (org.), Gobernar (en) la diversidad: Experiencias indígenas desde América Latina: Hacia la investigación de co-labor (pp. 34-5). México, DF: CIESAS, FLACSO Ecuador y FLACSO Guatemala.

Lyotard, J. F. (2004). A condição pós-moderna. Rio de Janeiro, RJ: José Olympio.

Marques, C.C., Palombini, A, Passos, E., \& Campos, O. R. T. (2013). Sobre mudar de lugar e produzir diferenças: A voz dos usuários de serviços públicos de saúde mental. Mnemosine, 9(1):106-126.

Mendes, E. V. (1993) Distrito sanitário: O processo social de mudanças das práticas sanitárias do Sistema Único de Saúde. São Paulo, SP: Hucitec.

Pedro, R. (2010). Sobre redes e controvérsias: ferramentas para compor cartografias psicossociais. In A. A. L. Ferreira, L. L. Freire, M. Moraes, \& R. J. J. Arendt (org.), Teoria ator-rede e psicologia (pp. 78-96). Rio de Janeiro, RJ: Nau.

Portaria No 336, 19 de fevereiro de 2002. Dispõe sobre os Centros de Atenção Psicossocial - CAPS, para atendimento público em saúde mental, isto é, pacientes com transtornos mentais severos e persistentes em sua área territorial, em regime de tratamento intensivo, semi-intensivo e não-intensivo. Diário Oficial da União, 20 de fevereiro de 2002.

Senna, L. L., \&Azambuja, M. A. (2019). Gestão autônoma da medicação: Saberes e visibilidades de usuários de saúde mental em universidades no interior do RS. Revista Pólis e Psique, 9(2): 67-86. https://doi.org/10.22456/2238$152 X .86774$

Spivak, G. C. (2010). Pode o subalterno falar? Belo Horizonte, MG: Editora UFMG.

Marcos Adegas de Azambuja

Professor do Departamento de Psicologia na Universidade Federal de Santa Maria, Santa Maria - RS. Brasil.

E-mail: marcos.azambuja@ufsm.br

(iD) https:// orcid.org/0000-0002-2451-1644

\section{João Leite Ferreira Neto}

Professor do Departamento de Psicologia da Pontifícia Universidade Católica de Minas Gerais, Belo Horizonte MG. Brasil. Bolsista de produtividade do CNPq.

E-mail: jleite.bhe@terra.com.br

(iD) https:// orcid.org/0000-0003-3900-508X

Endereço para envio de correspondência:

Centro de Ciências Sociais e Humanas. Departamento de Psicologia. Professor Marcos Adegas de Azambuja. Av.

Roraima, 1000, Cidade Universitária, Bairro Camobi. CEP: 97105-900. Santa Maria - RS. Brasil. 
Psicologia: Ciência e Profissão 2019 v. 39 (n.spe 2), e226200,74-86.

Recebido: $17 / 07 / 2019$

Aceito: 04/09/2019

Received:07/17/2019

Approved: 09/04/2019

Recibido: $17 / 07 / 2019$

Aceptado: 04/09/2019

Como citar: Azambuja, M. A., \& Ferreira Neto, J. L. (2019). Do território à multiterritorialidade entre usuários, trabalhadores e pesquisadores em saúde mental. Psicologia: Ciência e Profissão, 39(n.spe 2), 74-86. https://doi.org/10.1590/1982-3703003226200

How to cite: Azambuja, M. A., \& Ferreira Neto, J. L. (2019 From territory to the multi territoriality among users, workers, and researchers in mental health. Psicologia: Ciência e Profissão, 39(n.spe 2), 74-86. https://doi.org/10.1590/1982-3703003226200

Cómo citar: Azambuja, M. A., \& Ferreira Neto, J. L. (2019). Del territorio a la multiterritorialidad entre usuarios, trabajadores e investigadores en salud mental. Psicologia: Ciência e Profissão, 39(n.spe 2), 74-86. https://doi.org/10.1590/1982-3703003226200 